\title{
Unauthorized Curating. The Relations between Art Activism and the Museum
}

\begin{abstract}
The article focuses on art activism directed to museums and their sponsorship relationship with the oil industry. It considers the form and content of protests undertaken by art collectives such as Liberate Tate, BP, or not BP?, and Fossil Free Culture NL. The author recognizes the goals of activists in undermining the reality of capitalocene. She frames this form of protest with the term "unauthorized curating", which she derives from the analysis of participation paradigm and the definition of curatorial practice proposed by Marta Kosińska. Finally, she analyzes the strategy undertaken in art of protest.
\end{abstract}

Keywords: art activism, protest, capitalocene, unauthorized curating

Art activism directed towards museums has its own and long history. It was practiced in the form of the art world critique by artists such as Marcel Broodthaers, Daniel Buren or Hans Haacke, but also undertaken by collectives, among others by Art Workers Coalition, Black Emergency Cultural Coalition and Guerilla Girls group. This form of criticism concentrated particularly on revealing the impact of the institutionalization of values of art, art history's gaps, as well as the political and economic dependency of cultural institutions. The last field is also a subject of interest for groups to whom this article is dedicated. Art collectives aiming at cutting the ties between museums and the oil industry are the theme of my concern here. I am interested, in particular, in the relations between activists and institutions, that I try to frame using the concept of unauthorized curating and then analyzing its strategies.

The groups of activists, such as Liberate Tate, BP, or not BP?, and Fossil Free Culture NL are united under a common blanket of Art, not Oil coalition. They 
use and merge various tools of art to protest: performances, interventions, informative campaigns, as well as legal disputes with the institutions. Their struggle over the last few years to end sponsorship relations that bond museums and oil corporations are marked by successful milestones such as the breakup between Tate Gallery or Royal Shakespeare Company with BP, and Amsterdam van Gogh Museum with Shell company, announced in 2016 and 2018.

The initial point of activism was to acknowledge the role of museums in the so-called Carbon Web, "the network of relationships between oil and gas companies and the government departments, regulators, cultural institutions, banks and other institutions that surround them". ${ }^{1}$ The art practice is also framed by capitalocene, a concept proposed by James Moore (Moore 2016: 78-115), by which he describes the era originating in the $16^{\text {th }}$ century as the beginning of the process of commodification and exploitation of nature. The term covers not only the ecological consequences of capitalism, but also a mechanism or complex system that maintains the dominance of this formation of global order. One of its elements is constituted by museums which play a significant role in legitimizing particular visions of reality. Thus, activists focus, among others, on museums of natural history based on the colonial model of classification of people and nature. For instance, the Decolonize This Place group occupied the space of the New York Museum of Natural History in Anti-Columbus Day in October 2016. They led an unauthorized tour of the Museum's space, indicating the fragments on display that promote the superiority of humans over the natural world, such as the Akeley Hall of African Mammals which consisted of 28 habitat dioramas. Artist Vaimoana Litia Makakaufaki Niumeitolu, who participated in the event, proclaimed:

'Shot down, stuffed, and hauled to the museum for display, these species made their way here through the circuits of empire.' Rooted in colonial plunder, she explained, the project that began with the embalmed animals continues today with the ongoing expropriation of native land throughout the world for 'conservation,' with wildlife preserves that have been 'depopulated for the use of tourists, just as the tradition of indigenous resistance continues' (Chen 2016).

Yet another sort of entanglement of cultural institutions within the capitalocene network concerns the relationship between museums and corporations that profit from the policy of abusing nature. They are both connected through the situation of exchange: museums receive financial support and in return foster corporations in the symbolic sphere. By promoting logotypes and emphasizing the gratitude for donations, the positive image of the corporation is created as well as a peculiar license for activity is given. This "dirty" relationship can be described by the term artwash (Evans 2015), which refers to the strategy of "cleansing" the image of international corporations through involvement in the field of art. $^{2}$

1 https://platformlondon.org/about-us/platform-the-carbon-web/ (access: 16.02.2020).

2 The degree of these dependencies is varied, it differs due to the state models of the cultural sector and its funding. When the state support is limited and cultural institutions are subsidized 


\section{Extended participation}

The analyzed form of activism can be seen in the context of the ideas postulated by the new museology movement, especially the ones developed in Latin America which promote the vision of an engaged institution, relevant to the community and aimed at social change. This direction of specifying the museum role is present worldwide nowadays, for instance in a newly updated definition of the museum which gave rise to discussion by The International Council of Museums (ICOM) in $2019^{3}$. I would like to follow this part of the interpretation, yet with a focus placed on a particular area of the museum's social involvement. I will consider the art activism from the angle of a turn towards the audience, which is rooted in the new museology, and which found its best expression in the concept of a participatory museum.

Nina Simon characterized:

a participatory cultural institution as a place where visitors can create, share, and connect with each other around content. Create means that visitors contribute their own ideas, objects, and creative expression to the institution and to each other. Share means that people discuss, take home, remix, and redistribute both what they see and what they make during their visit. Connect means that visitors socialize with other people - staff and visitors - who share their particular interests. Around content means that visitors' conversations and creations focus on the evidence, objects, and ideas most important to the institution in question (Simon 2010).

The paradigm of participation and engaging museums has gained incredible acceptance, and has become a reference point for cultural institutions, an indication of the form and content of museum activity. However, the term was also the subject of criticism. Marcus Miessen, who analyzed the political aspects of participation, revealed the romantic and fictitious assumptions about a jointly developed consensus and co-harmony. He condemns the façade participation, which takes the form of pseudo-consultation, obscuring reality which is based on inequalities and conflicts (Miessen 2011: 13). Léontine Meijer-van Mensch in turn accentuated the challenges and complexity of participation fulfilled in museums, and reported how different implementations of the idea of participation have and how it influences the relationships between museum and stakeholders, the issue of authority and ethics (Meijer-van Mensch 2011). Meijer-van Mensch introduces an important distinction while analyzing the scope of involvement of community members within various participatory activities. She distinguishes the front and back stage of museums' activities, whilst the former relates to various events, such as educational projects and exhibitions, the latter includes collecting policy,

mainly through the private sector (such as in the United States), the process of breaking the chains is more arduous and requires systematic solutions.

3 https://icom.museum/en/news/icom-announces-the-alternative-museum-definition-thatwill-be-subject-to-a-vote/ (access: 2.08.2019). 
conservation or administrative issues. Both, as she exemplifies, can be realized through the participation of stakeholders in decision-making process.

The new paradigm involves an increased social engagement of museums, and this social engagement has two directions. On the one hand, museums show an interest in an expanded series of stakeholders but, at the same time, accept that new stakeholders show on their part an interest in the policy of museums. The concept of stakeholder does not necessarily refer to a party that visits or acts directly in the museum, but may be a party that acts directly or indirectly upon the museum instead (Meijer-van Mensch 2011: 117).

However, my reference to Meijer-van Mensch aims to show that in the case of analyzed art activism, the participation in "back-office" museum policy is not taken for granted. It is rather a subject of tensions and negotiations, in which activists strive for recognition as stakeholders with a right to impact the institution's strategic areas. The art of protest can be understood as an attempt to go beyond the demarcation line determining who has the decision-making power, to expand the participation model and to occupy the area previously reserved for experts. Activists challenging the ethically burdensome sponsorship want to influence the management and the financing policy of institutions. Because they are not invited to collaborate, they must enforce it by themselves. The projected and expected involvement is not offered nor legitimated by the institution in the given context. Hence, I propose to frame art activism as an unauthorized activity and - as I explain in the following part of the article - also interpreted as curatorial practice.

\section{Curating and the curatorial}

Marta Kosińska deconstructs the process of the historicization of art curating and reveals the premises which founded the linear narration about the curatorial profession. As she claims, the emergence of history of curating coincides with the manifestation of art labelled as institutional critique. Artists such as Marcel Broodthaers, Daniel Buren or Hans Haacke mentioned at the beginning of the article, made the curating a subject of multiple critiques. They demystified the neutrality of curatorial practices by various means, intercepted the curator's "tool" and exaggerated or transformed them. Their work influenced how the profession was comprehended: among others, as a producer of values and meanings, operating through gestures of selection and rejection. In relation to artists diagnoses, a new mode of curatorial work was developed: authorial, interdisciplinary, freelance, independent from the institution (with a precursor role of star-curator Harald Szeemann). Finally, curators appeared as the ones who perform multiple roles, applied skills and knowledge attributed not only to the art historian, but 
also to diplomats, critics, politicians, economists, who operate not only within the medium of exhibition but also curate events, programs and publications.

Further refigurations of curatorial practice were introduced by the new institutionalism movement (Ekeberg 2003), as well as the participatory paradigm. The first term was used to describe the attempts to redefine the contemporary art scene and were undertaken from within the institution by its curators or directors. The transformative effect was to create socially engaged research centers, dedicated rather to debates, workshops and processual art residencies than an exhibition format. The new institutionalism influenced how defining curating was redirected towards softer approaches and understood, for example, not as a profession but as a production of knowledge or "as a kind of software for the tedious process of reconciling the institutional framework of the Museum, Academy, Laboratory and Agora" (Kosińska 2014: 18).

Again, the idea of participation entailed the requirement of new competences, the ability to engage communities and respond to given reactions. Relations between the curator and the audience could no longer be defined as a one-way process but rather as fluid, multi-faceted, and giving sometimes unexpected results. Hence, the curator was adhered to facilitator, a collector of various perspectives, experiences and relations, an assistant accompanying the processes of experiencing knowledge (Gurian 2008). In the context of her/his cooperation with the artists, the curator was portrayed as a film director or an editor (Storr 2006: 20), who could consult or negotiate the final version of work with the contributors.

The short version of curatorial history that I tried to sketch out above is organized around the concept of curator movements from and to an institution, with an assumption of the oppositional relationship of both, as Kosińska recognizes. Firstly, the curator, in response to criticism received from artists, takes the role of the critic of themselves, at the same time selecting positionally independent from the institution. Then they return to an institutional frame to redefine it from within, in the process gaining new competences and transforming the tools of practice. This narration, although mapping the field and containing many accurate diagnoses, locates the curatorial practice outside the institution. The presupposition about the separation of these two things has been questioned among others, by Andrea Fraser, who understood institutions not as places or organizations of a particular form, but as a complex field of social relations (Fraser 2005). The institution is within us, as Fraser pointed out. Morever, Kosińska states that this linear narrative is written from a certain Western perspective, hence its incompleteness and schematic result.

Considering the above, the author proposes a different view of the curator's activity in order to release it from an essentializing view. She employs Pierre Bourdieu to:

replace the self-agency figure of a subjectified western curator by a broader concept of curatorial disposition? In turn to understand it as appearing at a given moment in the field of art as 
a set of features, occasions, configurations, possibilities, space for action filled with the possible at a given time and a given 'construction of social trajectory' (articulation) practices of taking place, creating conditions to act, move, take a position (Kosińska 2014: 37).

Kosińska apprehends the curatorial practice as a flexible and malleable position regarding cultural/art content and a set of potentialities that can be used by various social agents. Her proposal is opposed to indicating essential features that characterize the curatorial profession, instead it enables us to analyze the practices in different historical and social contexts and covers a wider range of curatorial roles and executions.

Kosińska's recognitions are in line with other inquires that consider curatorial practice in a broader sense and which coincides with the conceptualization of the "curatorial" term and how it diffirentiated from the "curating". As Jean-Paul Martinon and Irit Rogoff claim:

If 'curating' is a gamut of professional practices that had to do with setting up exhibitions and other modes of display, then 'the curatorial' operates at a very different level: it explores all that takes place on the stage set-up, both intentionally and unintentionally, by the curator and views it as an event of knowledge. So to drive home a distinction between 'curating' and 'the curatorial' means to emphasize a shift from the staging of the event to the actual event itself: its enactment, dramatization and performance. 'Curating' takes place in a promise; it produces a moment of promise, of redemption to come. By contrast, 'the curatorial' is what disturbs this process; it breaks up this stage, yet produces a narrative which comes into being in the very moment in which an utterance takes place (Martinon, Rogoff 2013: ix).

The curatorial has several denotations, it is considered as theoretical discourse, a series of existing knowledge and an attitude of challenging the field of praxis.

Kosińska introduces, among other things, Irit Rogoff's thoughts concerning curating/ curatorial into the proposal of locating curatorial (understood in terms of critical approach) in knowledge and practice orders at the same time. According to her, the curatorial practice is both a discursive and generating agency, it draws on and operates within the field of knowledge, but recognizes and modifies it through activity. It is a practice and simultaneous discursive work of constructing normative explanations. Thus, Kosińska suggests a concept of "knowing practice" which reflects this duality of curatorial practice. She also refers to framing, widely applied in curatorial's theoretizations, yet brings out its new meanings by providing the context of the aforementioned "knowing practice". Framing, again, gains an active dimension as it is considered to be taking a position in the field of social relations and making this positioning a subject of reflection.

Shifting the conceptualization of curators from the questions regarding profession (and thus tasks and duties) towards practice (action, disposition and strategy) allows to go beyond museum and exhibition contexts (Kosińska 2014: 40) and to notice different areas of curatorial activity such as building relationships, establishing artistic groups or galleries. In particular, it enabled Kosińska to analyze the field of art in post-war Poland and recognize that the curatorial position 
was then taken over by various agents: critics, artists, animators, gallerists, "who rarely resembled any version of the West Curator" (Kosińska 2014: 38).

From my perspective the concept of curatorial disposition as a set of possibilities and form of activity, opens up the potentiality of revealing yet other actors appearing in the field - the activists. How they fulfill the given space for actions will be the subject of the article's following part.

\section{Strategy of art of protest}

Although art activism has no limits in its medium or style (Lippard 1984: 342), as Paula Serafini convincingly states, the analyzed cases of art of protest often adopt performing arts. It is a result of the possibilities this medium offers, such as interventional character, collective, embodied and self-transformative experience, among others (Serafini 2018: 15-18). The groups varied in terms of applied esthetics: "While Liberate Tate adopts a somber, dignified, and minimalist aesthetic that is marked by the use of veils and black clothing and props, BP or not BP? uses theatricality and humor as its main weapons" (Serafini 2018: 183). The choices are motivated by individual preferences, the character of institution in which the intervention takes place and the goal that the group would like to reach (Serafini 2018: 183). What the collectives definitely share is the message they spread.

Dozens of black balloons filled with helium lifted up dead animals and filled the space of the Tate Modern Hall in one of the first performances of the group Liberate Tate Dead in the water (2010) organized on the occasion of the Tate's 10th Birthday. On the first anniversary of the explosion of the Deepwater Horizon (managed by BP) and the oil spill into the Gulf of Mexico, a naked huddled man lying at the Duveen Galleries in Tate Britain had an oil-like-substance poured over him (Human cost 2011). During the Floe Piece performance (2012), a group of activists transported a 55-kilo block of ice from the Occupy London protest headquarters in St. Paul's Cathedral to the Turbine Hall at Tate Modern. Then, in silence, they watched the melting of the ice sheet.

The image of the consequences of the fossil fuel industry is clear, it consists of dead animals, melting ice and the vulnerability of bodies. How are the mutual relations connecting institutions with oil corporations presented in activists' interventions?

The annual report published by Tate in September 2010 emphasized that sustainable development plays a key role in the institution's program, and also boasted of reducing carbon emissions. In the same month and the day before the Tate Supervisory Board meeting, 50 members of the Liberate Tate collective gathered in the Turbin Hall and spilled streaks of black paint, creating a shape reminiscent of the BP logotype. The work entitled Sunflower also announced the Ai Weiwei's 
exhibition which was shown in the gallery in the following months. The installation of the artist known for his political commitment consists of millions of porcelain sunflower seeds filling the space of the Turbine Hall.

Liberate Tate has repeatedly revealed the "hypocrisy" of the institution and its seemingly inclusive nature; as it was in the Gift performance (2012), when a group of artists gave a 17-meter-long wind turbine blade as a present for the Tate's collection. Despite environmental and local support for the donation, the gallery rejected it. When the Tate consistently refused to announce the amounts behind the sponsorship relationship with BP, the collective organized the Hidden Figures performance (2014), in which Kazimierz Malewicz's painting the Black Square presented at that time at Tate, played a key role. The iconic figure of the suprematist movement lost its stable form on canvas in favor of flexible woven fabric susceptible to the choreography of moving activists. The group has shown that art is not detached from reality as suprematism claims. The three-year dispute over the disclosure of data on financial support provided by BP, which involved law firms and non-governmental organizations, ended with in court when Tate were forced to make information public. The surprisingly low support prompted artists to scatter designed "BP/ Tate" banknotes in the space of the exhibition funded by the oil company and entitled BP Walk through British Art (performance The Reveal, 2015). Collective Fossil Free Culture NL performance Shell's Dirty Hands (2018) at Van Gogh Museum, during which the participants left black traces of hands on the museum building surface. In the intervention Writing on the Wall, staged a year later, the group of artists printed their oil-soaked bodies on the glass façade of the Royal Amsterdam greatest concert hall.

The aforementioned performances indicate the discrepancies between the values declared by the institutions and the factually realized programme, as well as highlighting the entanglement of cultural institutions within the capitalocene network. I assume that art activism can be considered in the frame of duality attributed to curatorial practice as it is discursive action, expressed by Kosińska as "knowing practice". On the one hand, the art interventions are based on recognition of museums' neutrality myth, in particular in the case of their financial status. They result in revealing the assumptions concerning the social role of the museum and the idea of the participation of local communities in institutions' policy. On the other hand, the undertaken actions contribute to transformations of the indicated premises. Through focusing on the chain of relations that connects the museum with fossil fuels and the latter with the exploitation of nature, art activism breaks the illusion about the neutrality of financial support which is rewarded by appreciation and social license to act. Moreover, the activists involve the institution in political protest, demanding a clear and direct action against oil corporations and climate change. They persuade museums towards activism, as they seem to repeat after Robert R. Janes and Richard Sandell: "This is a moral imperative for museums, as climate change is no longer just about science or politics - it is also 
about social justice" (Janes, Sandell 2019: 4). In addition, the protesting groups implement the idea of the democratization of institutional practice by occupying positions previously reserved for experts and increasing the range of people who have an impact on museum policy.

Paula Serafini however, frames these aspects of activism as intrinsically connected transgressions and prefiguration: "Transgressing spatial boundaries and the norms and dynamics of an institution opens up a space for art activist performances that propose another form of doing and experiencing art in that space, as a horizontal, democratic, and inherently political activity" (Serafini 2018: 83). According to this view, performance actions can be strategic and transgressive in reaching specific political goals, while at the same time prefiguratively enacting alternative forms of art making. In the latter context Serafini refers specifically to a method of cooperation and hierarchy within art groups as well as their relations with the audience and participants of performances, while I focus on activists' involvement in an institution's policy.

Paula Serafini in her book Performance Action. The Politics of Art Activism also addresses the issue of relations between activists and institutions and comprehends it as a site-specific art that is planned for particular locations, in many cases in regard to exhibitions and works of art presented at a given time in specific sites (Serafini 2018: 145-147). Yet she clearly emphasizes that the primary goal of activism is the environmental one: climate justice which is supposed to reach the fossil fuel industry, while the approaches toward institutions are more nuanced. Serafini situates the activists' practice outside the institutional framework, as the first grows out of another context that is political environmental struggles, the latter is organized around symbolic values.

For this reason, the transgressive interventions of groups targeting oil sponsorship of the arts act as temporary re-appropriations of space, in which the consensus of the museum is broken, its rules are bent and rejected, and the values and processes of activism triumph over those of institutional artistic practice. In this context, participatory performances bring political protest into the cultural institution: not a representation of protest, but the real thing (Serafini 2015: 205).

The introduction of this distinction was applied by Serafini to prove that activists succeed in resisting traps lurking in the process of operating with/within the institution, such as appropriation, self-censoring or dependence from organizations associated with the criticized one.

Finally, I would like to redirect the reflection on the (in)dependence of activism from/on institutions and try to provide a different angle - highlighting the mutual relation as a subject and a tool of activists' strategy which I describe as unauthorized curating. 


\title{
Unauthorized curating
}

By using the term unauthorized curating, I suggest a peculiar tactic based on the adjacency between the activists and institutions and their bilateral dependencies. The activists occupy the museums' space, organize performances, interventions, alternative tours and disrupt the site in a physical and symbolic way. These activities are not organized, ordered or legitimated by the museum (yet they could be recognizable as such, as I will elaborate on later). Moreover, oftentimes they are opposed to official museum policy or cultural programs and this even results in being reported to the police as being dangerous for the space and art pieces. ${ }^{4}$

However, art activism entangles the institution into an ethical discussion, it requires a response and reaction, gives no rise to indifference. In the following part I consider how the museum is being dragged into activists' struggles.

\begin{abstract}
Institutions are not monolithic unities. They are complex multiplicities, split within themselves and between themselves and their settings. Museums have custodial staff, administrators, curators, IT personnel, fundraisers, directors, donors, trustees, and visitors. They also have their broader cultural position, their reputation as sites of authoritative knowledge. This makes them sites worth seizing. When art activists commandeer a museum, they split it from within. The already existent divisions within the institution are activated. Anyone affiliated with the museum is forced to take a side: few or many, rich or poor, past or future? By occupying institutions, identifying allies on the inside, empowering employees, working with whistle-blowers, leveraging legal grey zones, and strategically mobilizing the symbolic power of key constituencies, activist art collectives redeploy the arsenals of power that have already been stored. The institution is liberated (Not An Alternative 2016).
\end{abstract}

This quotation comes from Institutional Liberation by Not An Alternative organization which works at the intersection of art, activism and theory. The text emphasizes the role of museums in maintaining and legitimizing neoliberal ideology and also describes the strategies chosen by activists. The collective mentions the process of reclaiming the cultural commons, referring to culture as common property and the hegemony of the institution in its management. Among the tactics applied, the artists describe commandeering and taking over the museum, that means to infect the institution with values and practices shared by the activists. The adopted strategy is a nuanced "Trojan horse" idea described in the classic essay by Lucy Lippard (1984). The artists smuggle into the institutional frame using means of artistic production yet instead of abolishing the museum "walls" the activism subversively challenges the protested structure.

The literal implementation of a trojan horse approach was a two-day long performance staged by BP or not BP? in February 2020 at the British Museum in correspondence with the Troy: Myth and Reality exhibition, financially supported by BP. Activists dressed as ancient Greek warriors smuggled a massive Trojan horse

4 https://www.fossilfreeculture.nl/portfolio/drop-the-shell/ (access: 23.03.2019). 
into the London museum, encouraging almost 1500 people to join the protest. The limited number of performers remained in the museum's Great Court long after its closure and used 'plaster casts, bodies, consent, tenderness and sustenance ${ }^{5}$ to create an artwork entitled Monument. Plaster casts of the gathered bodies were accreting during the night till they reached a form of sculpture drawn from bodies, histories, and experiences.

Performance actions not only attach to the institution's narrative but intercept it and present it in a re-configurated form. They adopt a tactic of controlled resemblance which can be exemplified by the case of the Liberate Tate and The Natural History Museum groups who have over-taken and simultaneously slightly changed the names and logotypes of Tate Gallery in London and the Museum of Natural History in New York. The art interventions in many cases seem to be a part of the museum program or commissioned performances. An outside observer, at first glance, may find it difficult to recognize the difference between the activist group and the institution they criticize; both belong to the same order of art and use the same language. However, the message is distinctive and the activists seem to operate through this tension, as they speak on behalf of and in opposition to the museum at the same time. The semantic shift in the created content relates to sponsorship cooperation, which is neutral in Tate's management opinion yet reveals its consequences in art interventions. Demonstrating the problematic character of the alliance and smuggling this message into the institutional frame, resembles prompting the operating manual with the hope that the museum will internalize it. It can be considered as a practice of mimicry which is a tactic of subversive camouflage.

To address the classical theory of mimicry by Homi Bhabha (1994) seems to be useful in the case of analyzed art activism. The discourse of mimicry, which was developed by Bhabha in the field of postcolonial studies, is constructed around an ambivalence. Mimicry emerges as the representation of a difference in the process of imitation. The gesture of imitation is not a simple repetition but repetition with difference, a form of resemblance that destabilizes the identity of entities involved, who become almost but not quite the same. The effect of mimicry is slippage, disruption of the subject of imitation, its "not-quite sameness".

The strategy of art activists as a practice of mimicry introduces into the institution's frame (as I repeat, also after Paula Serafini) the idea of the democratization of the art field and museum activism. Describing art activism as a form of unauthorized curating enables us to consider the mutual relations between activism and institution not as unequivocally opposed. It puts an emphasize on the within/ outside tension that is used by activists to reshape the museum.

The provided concept of unauthorized curating is related to two other proposals concerning curatorial methodology but develops them a step further. Shel-

5 https://bp-or-not-bp.org/monument/ (access: 2.03.2020). 
ley Ruth Butler and Erica Lehrer have encouraged scholars to participate in an intriguing exercise of curatorial dreaming. This is imagining exhibitions or interventions which respond to their own claims of the museum critique (Butler, Lehrer 2016). Maura Reilly, in turn, introduces an ethical component to curating, which she defines as a position against the hegemony of the art system of privileged white males and a western frame of reference. Reilly promotes "curatorial activism" (Reilly 2018), which is understood as the organization of exhibitions that undermine the dominant discourse and focus on artists excluded from the mainstream (the work of artists from outside Europe and the United States, queer artists, women, etc.).

Both ideas propose a critique of the art and institutional field reinforced by the attempt at its transformation. While the notion of unauthorized curating coincides with this concept, it also goes beyond. It does not limit the area of curatorial practice to the medium of exhibition and includes activities undertaken without institutional affiliation or approval. It should be also added that this idea does not exclude confrontational, neither opposed nor antagonistic relations between activism and museums engaging in "dialogue".

\section{Conclusion}

The concept of unauthorized curating has the potential to cover various initiatives that infect the museum with the aim of its transfiguration, that applies the inside/ outside position and implements a peculiar strategy to draw the museum into the framework of activity. Analyses of collectives as art activism usually relate to aesthetic, performativity and embodiment of protests, collective identity, forms of cooperation as well as politics and public sphere. The proposal to consider protests as acts of curating enables to deepen another area of reflection: surrounding the institutions that are the subjects of protest. This perspective unseals the institutional frames and practice through revealing various stakeholders and social agents who are involved or entangled, and who influence museums' politics. It broadens how the institutions are perceived, by emphasizing diverse forms of agency that fluctuate outside/inside the museums.

\section{Bibliography}

Bhabha H.K.

1994 Of Mimicry and Man: The Ambivalence of Colonial Discourse in: The Location of Culture, New York-London.

Butler S.R., Lehrer E.

2016 Curatorial Dreams: Critics Imagine Exhibitions, Chicago. 


\section{Chen M.}

2016 Some of the Exhibits at the Museum of Natural History Are... Not... Good... The Artist Collective Decolonize This Place Is Taking Their Anti-Imperialist Message To Cultural Institutions Across The World,

https://www.thenation.com/article/archive/some-of-the-exhibits-at-the-museum-of-natural-history-are-not-good/ (access: 10.09.2019).

Ekeberg J. (ed.)

2003 New Institutionalism Verksted \#1, Office for Contemporary Art Norway, Oslo.

Evans M.

2015 Artwash: Big Oil and the Arts, London.

\section{Fraser A.}

2005 From the Critique of Institutions To an Institution of Critique, "Artforum", vol. XLIV, no. 1, p. 278-283.

Gurian E.

2008 The Essential Museum, “The Informal Learning Review”, no. 89, March-April, p. 1-7.

Janes R., Sandell R.

2019 Museum Activism, Abingdon-New York.

Kosińska M.

2014 Być może nie był kuratorem i nie działał w pojedynkę in: K. Sikorska et al. (eds), Zawód kurator, Poznań, p. 15-50.

Lippard L.R.

1984 Trojan Horses: Activist Art and Power in: B. Wallis (ed.), Art after Modernism: Rethinking Representation, New York, p. 341-355.

Martinon J.P., Rogoff I.

2013 Preface in: J.P. Martinon (ed.), The Curatorial: A Philosophy of Curating, London.

Meijer-van Mensch L.

2011 New Challenges, New Priorities: Analyzing Ethical Dilemmas From a Stakeholder's Perspective in the Netherlands, "Museum Management and Curatorship", vol. 26, no. 2, p. 113-128.

Miessen M.

2011 The Nightmare of Participation (Crossbench Praxis as a Mode of Criticality), New York.

Moore W.J.

2016 The Rise of Cheap Nature in: J.W. Moore (ed.), Anthropocene or Capitalocene? Nature, History, and the Crisis of Capitalism, San Francisco, p. 78-115.

Not An Alternative 2016 Institutional Liberation, "e-flux”, vol. 77, https://www.e-flux.com/journal/77/76215/institutional-liberation/ (access: 2.02.2020). Reilly M.

2018 Curatorial Activism. Towards an Ethics of Curating, London.

Serafini P.

2015 Prefiguring Performance, “Third Text”, vol. 29 (3), p. 195-206.

2018 Performance Action. The Politics of Art Activism, Abingdon-New York. Simon N.

2010 The Participatory Museum, http://www.participatorymuseum.org/read/ (access: 23.03.2019). 
Storr R.

2006 Show and Tell in: P. Marincola (ed.), Questions of Practice: What Makes a Great Exhibition?, Philadelphia.

Internet sources:

https://bp-or-not-bp.org/monument/ (access: 2.03.2020).

https://www.fossilfreeculture.nl/portfolio/drop-the-shell/ (access: 23.03.2019).

https://icom.museum/en/news/icom-announces-the-alternative-museum-definition-that-will-be-subject-to-a-vote/ (access: 2.08.2019).

https://platformlondon.org/about-us/platform-the-carbon-web/ (access: 16.02.2020). 